Jurnal Kesehatan Masyarakat

\title{
Fertility in North Sumatera: Why is it not declining?
}

Mugia Bayu Rahardja ${ }^{1 凶}$, Wisnu Fadila ${ }^{1}$, and Rahmadewi ${ }^{1}$

${ }^{1}$ Research Center for Population Research, BKKBN

Article Info

Article History:

Submitted September 2020

Accepted October 2020

Published March 2021

Keywords:

proximate determinants,

fertility, marriage, con-

traception, breastfeeding.

DOI

https://doi.org/10.15294/

kemas.v16i3.26138

\begin{abstract}
The results of the Indonesia Demographic and Health Survey (IDHS) in 2017 confirm that although the prevalence of contraception is quite high, the fertility rate in North Sumatera Province is still high. Fertility decomposition analysis has been used extensively to identify changes in fertility in various countries. This study was conducted to determine the pattern of changes in fertility decomposition in North Sumatra by using IDHS data in 2002/03 and 2017. The total fertility rate (TFR) from 2002 to 2017 in this province relatively remains the same, which is around 3 children per woman. There was a change in the proximate contribution of the determinant of fertility. Contraceptive use and effectiveness are the main contributors affecting the fertility rate in North Sumatra Province. The contribution of breastfeeding patterns has increased and marital patterns have decreased over a period of 15 years. The implementation of population and family planning programs in North Sumatra Province needs to be continuously improved to reach a TFR of 2.1 children per woman by 2024. Promotion of exclusive breastfeeding needs to be encouraged to extend the birth interval and reduce natural fertility. Prevention programs for child marriage and teenage pregnancy should be promoted.
\end{abstract}

\section{Introduction}

The family planning program in Indonesia has succeeded in reducing the fertility rate massively (Angeles, Guilkey and Mroz, 2005). In the period 1971-2000 there was a consistent decline in fertility from 5.6 to 2.34 children per woman (Central Statistics Agency, 2016). However, after 2000, the fertility rate in Indonesia experienced stagnation (stalling fertility). Results of the Indonesia Demographic and Health Survey (IDHS) shows that the birth rate is stagnant at 2.6 children per woman according to the 2012 IDHS results (BPS et al., 2013).

The budget allocation for population and family planning (KB) programs has been increased in response to the stagnation of fertility in Indonesia. IDHS results in 2017 show that the total fertility rate has decreased to 2.4 children per woman. This confirms that the birth rate in Indonesia must continue to be managed through population development and family planning, not only to reduce the birth rate but also to maintain the fertility rate to support long-term development (Samosir, 2019). Trends in fertility rates vary at the provincial level, which indicates the need for population and family planning development planning in accordance with regional conditions. In this regard, it is important to understand the proximate determinants of fertility, namely marital behavior, contraception, abortion, and breastfeeding, which have a direct contribution to the fertility rate.

The results of previous research conducted by Samosir in 2019 on the fertility decomposition analysis based on the IDHS results in 2017 which show that the main factors among the proximate determinants that affect fertility rates are the use and effectiveness 
of contraception. This means that in general the fertility rate in Indonesia is still very dependent on the presence of population management programs, especially the family planning program. North Sumatra Province is a unique region because the fertility rate in the province is still quite high, although in general the rate of contraceptive use is high. With an area of $72,981 \mathrm{~km} 2$, this province has a geographical condition that varies from mountainous areas, beaches, lowlands, and small islands separated from the main island. This creates challenges in providing access to health services and others. In addition, this province is inhabited by various ethnicities such as the Batak, Javanese, Chinese, Malay, Nias, and several other ethnic minorities, which causes a variety of cultures to live in the people of North Sumatra.

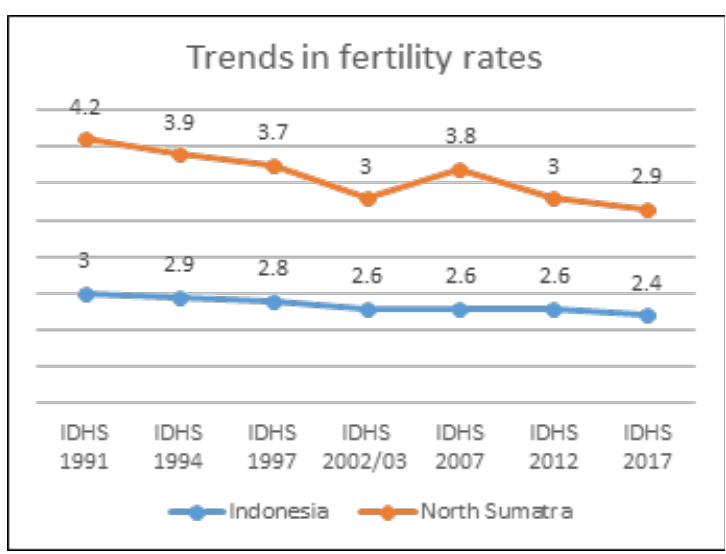

Figure 1. Trends in Fertility Rates, IDHS 19912017

Figure 1 shows a declining trend in the fertility rate in North Sumatra, but is still higher than the national fertility rate. The fertility rate of North Sumatra Province is 2.9 children per woman and the contraceptive prevalence rate is 59 percent. This phenomenon is associated with low long-term contraceptive use and high rates of contraceptive withdrawal (Wilonoyudho and Prajanti, 2018). The results of previous research indicate that sociocultural factors in North Sumatra Province greatly influence the fertility preferences of the people (Sitorus, 2020). The Batak tribe in North Sumatra Province is known for its community customs which regulate the path of descent from the father's side (patrilineal). This study is different from previous studies, because it compares between two different data sources and performs projections of fertility decomposition factors. This research focuses on changes in the fertility decomposition pattern in North Sumatra Province. This is interesting, because the analysis of fertility decomposition using IDHS data in 2002/03 and 2017 in North Sumatra Province has never been done before.

\section{Metode}

The data sources in this analysis are the results of IDHS in 2002/03 and IDHS in 2017 with the unit of analysis being the aggregate data of women of reproductive age is 15-49 years old in North Sumatra Province. The data used were IDIR41FL and IDIR71FL which were downloaded from the dhsprogram.com website. The research variables included total fertility rate (TFR), total marital fertility rate (TMFR), and total natural marital birth rate (total natural marital fertility rate / TNMFR), total fecundity rate (TF), marital index $(\mathrm{Cm})$, non-contraceptive index $(\mathrm{Cc})$, abortion index (Ca), and infertility index during breastfeeding (Ci).

The analysis in this study is divided into 3 parts. In the first part, the analysis focuses on the fertility decomposition based on the IDHS $2002 / 03$. In this case, the context of the analysis will be linked to population and family planning programs in the early days of decentralization. In the second part, the analysis will focus on the results of the fertility decomposition based on the results of IDHS in 2017 as a reflection of the 15 years of decentralization of population and family planning programs. In the third part, the analysis is focused on the comparison of the fertility decomposition of North Sumatra Province based on the results of IDHS in 2002/03 with the results of IDHS in 2017. In addition, an analysis of the policy direction for the decline in the fertility rate is also carried out. This research framework refers to the framework of Davis and Blake's fertility theory developed by Bonggarts so that it can be operationalized mathematically (Bongaarts, 1978; Hobcraft and Little, 1984). This theoretical framework has been used extensively to identify reasons for decreased fertility (Samosir, 1994; Das et al., 2013; Rutayisire, Hooimeijer and Broekhuis, 2014; Rutaremwa et al., 2015; Chola and 
Michelo, 2016; Lailulo and Sathiya Susuman, 2018; Jiang et al., 2019), using the following equation:

$$
\mathrm{TFR}=\mathrm{Cm} \times \mathrm{Cc} \times \mathrm{Ca} \times \mathrm{Ci} \times \mathrm{TF}
$$

\section{Results and Discussion}

The results of the calculation of research variables and indexes (TFR, TMFR, $\mathrm{Cm}, \mathrm{fy}, \mathrm{fm}$, e, Cc, APK, TNMFR, i, Ci, and TF) of North Sumatra Province based on IDHS in 2002/03 and IDHS in 2017 are presented in table 1. Fertility decomposition based on IDHS in $2002 / 03$. In the era of decentralization, district / city governments are required to be able to manage resources independently. Most district / city governments are still faced with the problem of low regional income and limited quality of human resources. In addition, strengthening family planning institutions in the regions is also one of the goals of revitalizing the Population and Family Planning program which has decreased since regional autonomy. IDHS results in 2002/03 can be used as an illustration of the achievements of the population and family planning program in Indonesia.

The results of data processing show that the estimated TMFR of North Sumatra Province is 4.70 children per married woman, meaning that the pattern of marriage in North Sumatra Province causes the fertility rate in marriage (TMFR) to be around 1.7 children per woman when compared to the rate of births overall (TFR). The marriage index based on the results of IDHS in 2002/03 shows that in North Sumatra Province is 0.64 . This implies that women spend about 64 percent of their reproductive years in married status with the possibility of bearing children.

The annual contraceptive failure rate in North Sumatra Province is based on the IDHS results in 2002/03 by 4 percent and the monthly contraceptive failure rate was 0.34 percent. Furthermore, the contraceptive effectiveness rate in North Sumatra was 96.59 percent. Based on the contraceptive effectiveness figure, the North Sumatra non-contraceptive index is 0.41 . This indicates that the fertility-reducing effect of contraceptive use and effectiveness in North Sumatra is 41 percent. This also means that 59 percent of women of reproductive age who are married and are not sterile are protected by contraception and are 100 percent effective.

Based on the non-contraceptive index above, the natural fertility rate (TNMFR) in North Sumatra is 11.41 children per married woman. The pattern of contraceptive prevalence and effectiveness resulted in currently married women in North Sumatra having fewer births, namely 6.71 births (TNMFR-TMFR $=11.41$ $4.70=6.71)$. The prevalence and effectiveness of contraception has resulted in a sizable difference between TMFR and TNMFR of around 7 children per currently married woman. In this case, the prevalence and effectiveness of contraception in North Sumatra can significantly reduce fertility rates.

IDHS results in 2002/03 also shows that the median infertility during breastfeeding (i) in North Sumatra is 2.7 months. This value of i produces an infertility index value during breastfeeding $(\mathrm{Ci})$ of 0.94 . This means that the fertility-limiting effect of breastfeeding patterns in Indonesia is 94 percent. Based on the infertility index value during breastfeeding above, the fertility rate in marriages without contraception, intentional abortion, and breastfeeding (TF) in North Sumatra is 12.1 children per currently married woman. This also means that the pattern of breastfeeding has resulted in married women in North Sumatra having fewer TF-TNMFR $=12.10-11.41=0.68$ births. 
Table 1. The Results of the Calculation of Research Variables and Indexes for North Sumatra Province Based on the Results of the IDHS in 2002/03 and the IDHS in 2017

\begin{tabular}{lccl}
\hline \multicolumn{1}{c}{ Variable / Index } & $\begin{array}{c}\text { IDHS in } \\
\mathbf{2 0 0 2 / 0 3}\end{array}$ & $\begin{array}{c}\text { IDHS in } \\
\mathbf{2 0 1 7}\end{array}$ & Unit \\
\hline Total fertility rate/TFR & 3,00 & 2,93 & children per woman \\
& 4,70 & 4,67 & $\begin{array}{l}\text { children per married } \\
\text { woman }\end{array}$ \\
Total marital fertility rate/TMFR & 0,64 & 0,63 & \\
Marriage index $\left(C_{m}\right)$ & 4,00 & 2,60 & percent per year \\
Contraceptive failure rate at 12 months $\left(f_{y}\right)$ & 0,34 & 0,22 & percent per month \\
Contraceptive failure rate per month $\left(f_{m}\right)$ & 96,59 & 97,79 & Percent \\
Contraceptive effectiveness $(e)$ & 0,41 & 0,33 & t \\
Non-contraceptive index $(C)$ & 51,6 & 58,0 & percent \\
contraceptive prevalence rate/CPR & 11,41 & 14,12 & children per married \\
Total natural marital fertility rate/TNMFR & 2,70 & 4,10 & month \\
The median duration of infertility after giving birth $(i)$ & 0,94 & 0,88 & \\
Infertility index during breastfeeding $\left(C_{i}\right)$ & 12,10 & 15,96 & $\begin{array}{l}\text { children per married } \\
\text { Total fecundity rate/TF }\end{array}$ \\
\hline
\end{tabular}

Results of the IDHS in 2017 in this study assumed to be a reflection of the implementation of decentralization of population and family planning programs for about 15 years. Changes towards increasing the implementation of population and family planning programs nationally were made during this period. These changes include an increase in the budget and implementation strategies for population and family planning programs in the field lines. The fertility rate of North Sumatra Province is based on the IDHS results in 2017 was 2.93 children per woman. In this case, it can be said that there has been no significant change from the results of the population and family planning programs which are reflected in the achievements of the TFR in North Sumatra during the period 2002 to 2017.

After the decentralization of population and family planning programs for about 15 years, the fertility rate of North Sumatra Province is based on the IDHS results in 2017 it is still included in the category of areas with high fertility rates (3 children per woman). The results of data processing show that the estimated TMFR of North Sumatra Province in 2017 is 4.67 children per married woman, meaning that the pattern of marriage in North Sumatra Province causes the rate of fertility in marriage (TMFR) to be around 1.7 children per woman compared to the number overall birth (TFR). The marriage index based on the IDHS in 2017 is 0.63 , meaning that women in the province of North Sumatra spend 63 percent of their reproductive years in married status and are exposed to the possibility of giving birth to children.

The annual contraceptive failure rate in North Sumatra Province is 2.6 percent and the monthly contraceptive failure rate is 0.22 percent. Furthermore, the contraceptive effectiveness rate in North Sumatra is 97.79 percent. Based on the contraceptive effectiveness figures, the North Sumatra noncontraceptive index $(\mathrm{Cc})$ is 0.33 . This shows that 67 percent of women of reproductive age who are married and are not sterile are protected by contraception which is 100 percent effective.

Based on the non-contraceptive index above, the natural fertility rate / TNMFR in North Sumatra is 14.12 children per married woman. This means that the pattern of contraceptive prevalence and effectiveness has resulted in currently married women in North Sumatra having fewer births, namely 9.45 births. The effect of reducing fertility (fertilityreducing effect) in North Sumatra with $\mathrm{Cc}=$ 0.33 , which means that the prevalence and effectiveness of contraception has resulted in a sizable difference between TMFR and TNMFR, 
around 9 to 10 children per married woman. In this case, the prevalence and effectiveness of contraception in North Sumatra has significantly reduced the fertility rate in North Sumatra. The results of the IDHS in 2017 show that the median infertility during breastfeeding (i) in North Sumatra is 4.1 per months. This value of $i$ results in an infertility index value during breastfeeding $(\mathrm{Ci})$ of 0.88 . This means that the effect of fertility-limiting from breastfeeding patterns in Indonesia is 88 percent. Based on the infertility index value during breastfeeding above, the fertility rate in marriages without contraception, intentional abortion, and breastfeeding (TF) in North Sumatra is 15.96 children per married woman. This also means that the pattern of breastfeeding has resulted in married women in North Sumatra having fewer TF-TNMFR $=15.96-14.12=1.84$ births .

During the 15 year period from 2002 to 2017, the total fertility rate in North Sumatra did not change significantly, namely around 3 children per woman. Theoretically, the direct factor of fertility is influenced by several indirect factors, including social, demographic, economic and cultural factors. North Sumatra with its Batak ethnicity is known as one of the regions in Indonesia that holds tightly to patrilineal culture (paternal lineage), meaning that the presence of sons is an important thing in the family (Gultom, 2017) Batak tribal communities, in terms of the number and sex of children, greatly affect the fertility rate in North Sumatra (Sitorus, 2020). Figure 3 shows the change in fertility measures in North Sumatra based on the IDHS results in 2002/03 and IDHS in 2017. Contraceptive use and effectiveness factors remain the factors that have the greatest influence on the decline in fertility compared to marriage patterns and breastfeeding patterns.

In 2017 the pattern of contraceptive use and effectiveness has succeeded in preventing the birth of as many as 7.38 children per woman. There was an increase of 0.67 children per woman compared to the condition in $2002 / 03$. This resulted from an increase in the contraceptive prevalence rate by 6.5 percent in the same year period (from $51.6 \%$ in $2002 / 03$ to $58 \%$ in 2017). In other words, an increase in contraceptive prevalence by 6.5 percent was only able to prevent birth by 0.67 children per woman. The total fecundity rate increased from 12 children per woman in 2002 to around 16 children per woman in 2017. Furthermore, the factor of infertility after childbirth has also increased. The change in index from 0.94 in 2002 to 0.88 in 2017 shows that there has been an improvement in breastfeeding patterns and has a direct impact on decreasing the fertility rate in North Sumatra.

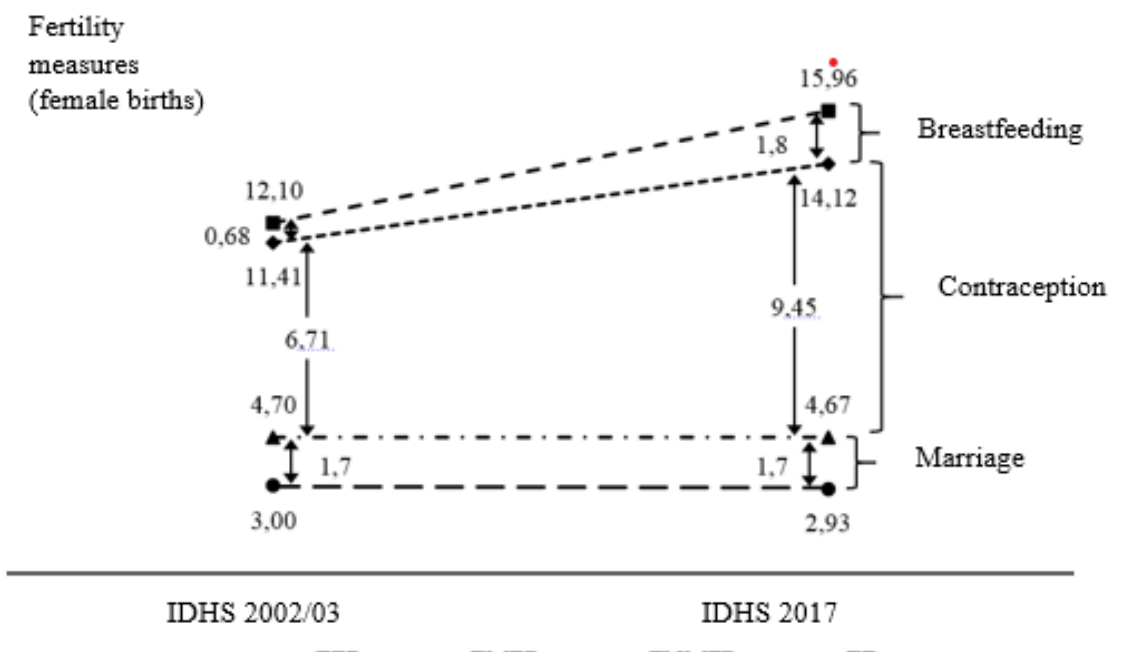

Figure 2. Change in Fertility Measure for North Sumatra Province Source: IDHS data in 2002/03 and 2017 (processed) 
The marriage index in North Sumatra also did not change significantly. The results of data processing show that over the past 15 years from 2002 to 2017, the marriage index was relatively constant at 0.63 . This means that about 63 percent of the woman's reproductive period is in married status. Figure 2 also illustrates that efforts to reduce TFR by increasing the prevalence of contraception are quite optimal. This can be seen based on the results showing that prevented births as a result of contraceptive use and effectiveness increased significantly from 6.71 to 9.45 . However, the impact is less significant for the decrease in TFR. This is likely closely related to the influence of other factors such as cultural factors in the local community regarding the preference for the number and sex of children (Samosir et al., 2018; Sitorus, 2020). In this case, the possibility of using contraception is more intended to space births and not to limit births. In addition, it is necessary to study further regarding the dropout rate and longterm use of contraception (Wilonoyudho and Prajanti, 2018). The last thing is closely related to access to contraceptive services, especially in areas with unfavorable geographical conditions (Paulus and Lette, 2019).

Table 2. Prevented Births and the Percentage Relative to Each Index in North Sumatra Province

\begin{tabular}{lcccc}
\hline \multirow{2}{*}{\multicolumn{1}{c}{ Indexs }} & \multicolumn{2}{c}{ Prevented birth } & \multicolumn{2}{c}{ \% Relative } \\
\cline { 2 - 5 } & $\mathbf{2 0 0 2 / 0 3}$ & $\mathbf{2 0 1 7}$ & $\mathbf{2 0 0 2 / 0 3}$ & $\mathbf{2 0 1 7}$ \\
\hline Ci, breastfeeding patterns & 0.68 & 1.84 & 7.5 & 14.1 \\
Cc, contraceptive patterns & 6.71 & 9.45 & 73.8 & 72.5 \\
Cm, marriage pattern & 1.70 & 1.74 & 18.7 & 13.4 \\
Total (TF-TFR) & 9.09 & 13.03 & 100.0 & 100.0 \\
\hline Soth
\end{tabular}

Source: IDHS data in 2002/03 and 2017 (processed)

Total prevented births (TF-TFR) in 2002 were around 9 births, while in 2017 it was 13 births. The effect of contraceptive use patterns and effectiveness on the decline in fertility rates is the highest compared to other proximate determinants of fertility (Table 2). This is experienced by almost all countries in Southeast Asia and South Asia, where contraceptive use is strongly influenced by the family planning program (Yeung, Desai and Jones, 2018). Overall contraceptive use and effectiveness patterns contributed around 73 percent to the decline in fertility rates in North Sumatra. The contribution of breastfeeding patterns to the decline in fertility rates increased quite significantly in the period 2002-2017. This increase is indicated by the change in its relative percentage from 7.5 percent in 2002 to 14 percent in 2017.

The contribution of the marriage pattern to the fertility rate in this province has decreased slightly, from 19 percent in 2002 to 13 percent in 2017. The contribution of the marriage pattern to fertility is not only related to the proportion of women with married status but also related to the age of first marriage. (Bongaarts) , 1982; Islam, 2017; Jiang et al., 2019) Both of these are strongly influenced by the socio-economic level of society and the opportunity to work for women (Jones and Gubhaju, 2011; Utomo, 2012; Correia, Rodrigues and Barros, 2014; Majumder and Ram, 2015; Yeung, Desai and Jones, 2018). 


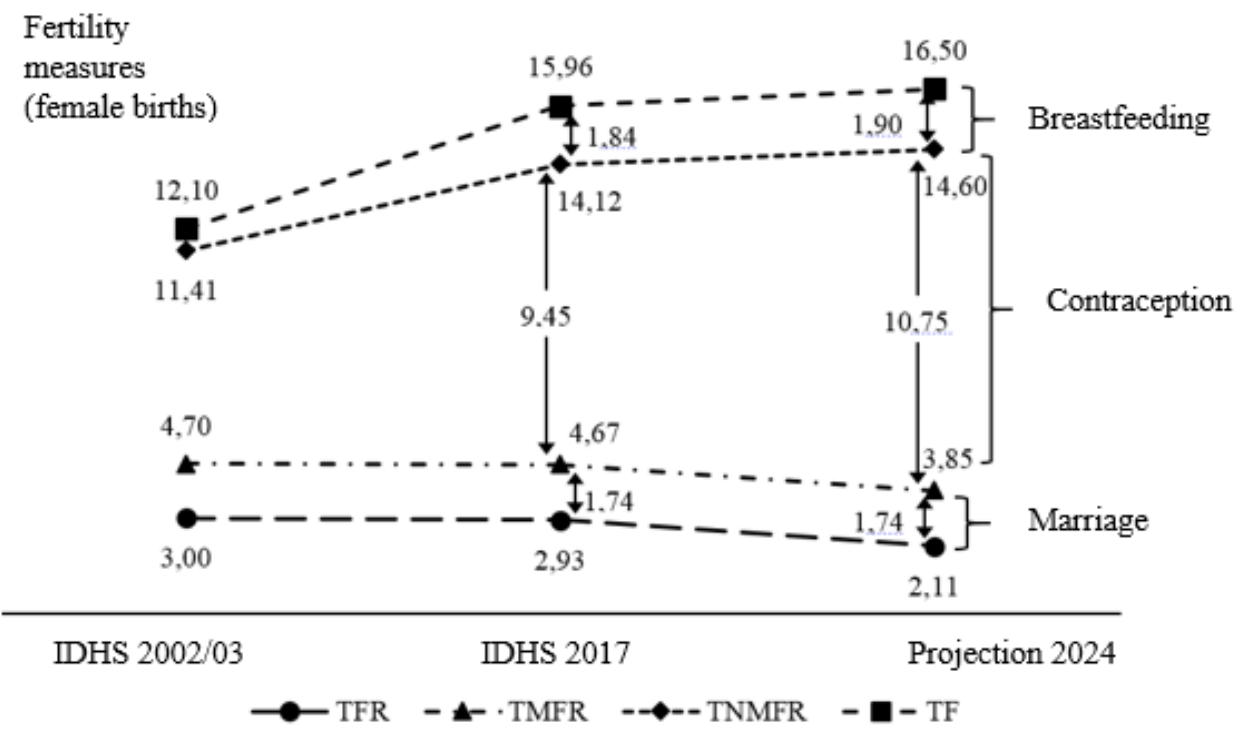

Figure 4. Changes and Projections in Fertility Measures for North Sumatra Province Source: IDHS data in 2002/03 and 2017 (Processed)

The TFR target for North Sumatra Province in 2024 as stated in the planning document is 2.11 children per woman. Based on the TFR target for 2024 and other assumptions for changes in fertility measures, the TMFR, TNMFR and TF follow a linear pattern. From this assumption, the marriage index, noncontraception index and breastfeeding index can also be calculated. Changes in the fertility decomposition pattern between the two IDHS periods and the projection for 2024. indicate that contraceptive use and effectiveness patterns are still the main contributing factors in reducing birth rates in 2024 (Figure 4). The minimum contraceptive prevalence rate that must be achieved is around 64 percent which will affect around 11 births prevented by 2024 . If the contraceptive prevalence can exceed this target, the number of births that can be prevented will also increase. The infertility index during breastfeeding in 2024 is projected to be 0.88 which contributes to preventing 1.9 births with the median infertility during breastfeeding being 4.1 months. The long duration of breastfeeding has the effect of inhibiting ovulation and thereby extending the birth interval. So that, a longer duration of breastfeeding will directly affect the decrease in fertility rates (Bongaarts, 1982; Bongaarts and Potter, 1983; Sipsma, Bradley and Chen, 2013; Malarcher et al., 2016).
Table 3. Proximate Index Projection of Determinants, Prevented Births and Relative Percentage in North Sumatra Province

\begin{tabular}{lccc}
\hline \multicolumn{1}{c}{ Index } & $\begin{array}{c}\text { Projection } \\
\text { in 2024 }\end{array}$ & $\begin{array}{c}\text { Prevented } \\
\text { birth }\end{array}$ & $\begin{array}{c}\% \\
\text { Relative }\end{array}$ \\
\hline $\begin{array}{l}\text { Ci, breastfeeding } \\
\text { patterns }\end{array}$ & 0.88 & 1.90 & 13.2 \\
$\begin{array}{l}\text { Cc, contraceptive } \\
\text { patterns }\end{array}$ & 0.26 & 10.75 & 74.7 \\
$\begin{array}{l}\text { Cm, marriage } \\
\text { pattern }\end{array}$ & 0.55 & 1.74 & 12.1 \\
$\begin{array}{l}\text { Total (TF-TFR) } \\
\text { Source: IDHS data in 2002/03 and } 2017 \text { (processed) }\end{array}$
\end{tabular}

The contribution of the three proximate determinants of fertility affected 14.4 births prevented. The factor with the highest contribution in reducing births was still the pattern of contraceptive use and effectiveness, namely around 75 percent, followed by breastfeeding around 13 percent and marital patterns at 12 percent. Therefore, these findings further emphasize the importance of government programs and commitments at all levels to control fertility rates (Rutayisire, Hooimeijer and Broekhuis, 2014; Jiang et al., 2019). However, in the future it is possible that the contribution of non-contraceptive factors will be more prominent than the use of contraception (Das et al., 2013; Majumder and Ram, 2015; Islam, 2017; Lailulo and Sathiya Susuman, 2018; Jiang et al. , 2019). The 
pattern of contraceptive use and effectiveness remain the main determinants of fertility in North Sumatra. This shows that the use and effectiveness of contraceptives has the greatest contribution to reducing fertility. The effect of breastfeeding patterns on fertility has increased. In contrast, the effect of marriage patterns on fertility has decreased over a period of 15 years.

\section{Conclusion}

During the period 2002 to 2017 there has been a change in the proximate pattern of determinants of fertility in North Sumatra, but has not been able to significantly reduce the TFR. Contraceptive use and effectiveness remain the main determinants of fertility in North Sumatra. To achieve the TFR target of 2.11 children per woman by 2024, it must prevent 14 births per woman from a TF of 16.50. This can be achieved if the CPR target of 64 percent is met and encourages long-term use of contraceptives. Married women should still be encouraged to use contraception as part of efforts to plan a family and create a quality family. The quality of contraceptive services needs to be improved to ensure its effectiveness and to maintain and increase contraceptive use. Strengthening information services on women's health and reproductive rights with the aim of being able to determine the number of children desired in the family.

The contribution of marriage patterns in reducing fertility has decreased, so that programs to delay the age of marriage and the prevention of teenage pregnancy must be promoted. Conversely, the contribution of the breastfeeding factor has increased. Therefore, it is important to maintain the promotion of breastfeeding for a longer period. In addition to getting the benefits of meeting the nutritional needs of the baby, breastfeeding can also widen the distance between births, thereby reducing fertility. In an effort to reduce fertility in this province, apart from the use and effectiveness of contraceptives, the factors of marriage and breastfeeding still need consideration.

\section{References}

Angeles, G., Guilkey, D.K., \& Mroz, T.A., 2005. The Effects of Education and Family Planning Programs on Fertility in Indonesia. Economic
Development and Cultural Change, 54(1), pp.165-201.

Badan Pusat Statistik, 2016. Profil Penduduk Indonesia SUPAS201. Hasil 5. Jakarta, Indonesia

Bongaarts, J., 1978. A Framework for Analyzing the Proximate Determinants of Fertility. Population and Development Review, 4(1), pp.105-132.

Bongaarts, J., 1982. The Fertility-Inhibiting Effects of the Intermediate Fertility Variables. Studies in Family Planning, 13(6), pp.179-189.

Bongaarts, J., \& Potter, R.G., 1983. Fertility, Biology, and Behavior: An Analysis of the Proximate Determinants. Population and Development Review, 9(3), pp.544.

BPS., 2013. Indonesian Demographic and Health Survey. Jakarta, Indonesia.

Chola, M., \& Michelo, C., 2016. Examining Underlying Determinants of Fertility Rates in Zambia: Evidence from the 2007 Zambia Demographic and Health Survey. African Population Studies, 30(2).

Correia, S., Rodrigues, T., \& Barros, H., 2014. Socioeconomic Variations in Female Fertility Impairment: A Study in a Cohort of Portuguese Mothers. BMJ Open, 4(1), pp.1-9.

Das, K.C., Chander, S., \& Nguyen, T.N.L., 2013. Proximate Determinants and Their Influences on Fertility Reduction in Vietnam. AsiaPacific Population Journal, 28(2), pp.5-25.

Davis, K., \& Blake, J., 1956. Social Structure and Fertility: An Analytic Framework. Economic Development and Cultural Change, 4(3), pp.211-235.

Gultom, E.R., 2017. Development of Women Position in the Patrilineal Inheritance of Indonesian Society. Jurnal Dinamika Hukum, 17(2), pp.194.

Hobcraft, J., \& Little, R.J.A., 1984. Fertility Exposure Analysis: A New Method for Assessing the Contribution of Proximate Determinants to Fertility Differentials. Population Studies, 38(1), pp.21-45.

Islam, M.M., 2017. Rapid Fertility Decline in Oman: Understanding the Role of Proximate Determinants. Middle East Fertility Society Journal, 22(4), pp.275-284.

Jiang, Q., Yang,S., Li, S., \& Feldman, M.W., 2019. The Decline in China's Fertility Level: A Decomposition Analysis. Journal of Biosocial Science, 51(6), pp.785-798.

Jones, G., \& Gubhaju, B., 2011. Trends in Age at Marriage in the Provinces of Indonesia. SSRN Electronic Journal, 105. 
Lailulo, Y.A., \& Sathiya, S. A., 2018. Proximate Determinants of Fertility in Ethiopia: Comparative Analysis of the 2005 and 2011 DHS. Journal of Asian and African Studies, 53(5), pp.733-748.

Majumder, N., \& Ram, F., 2015. Explaining the Role of Proximate Determinants on Fertility Decline Among Poor and Non-poor in Asian Countries. PLoS One, 10(2), pp.1-27.

Malarcher, S., Spieler, J., Fabic, M.S., Jordan, S., Starbird, E.H., \& Kenon, C., 2016. Fertility Awareness Methods: Distinctive Modern Contraceptives. Global Health Science and Practice, 4(1), pp.13-15.

Paulus, A.Y., \& Lette, A.R., 2019. The Effect of Physical and Socio-cultural Environments on the Access of Family Planning Service in Poor Couples of Reproductive Age in Sabu Raijua Regency. KEMAS: Jurnal Kesehatan Masyarakat, 15(2), pp.258-268.

Rutaremwa, G., Galande, J., Nviiri, H.L., Akiror, E., \& Jhamba, T., 2015. The Contribution of Contraception, Marriage and Postpartum Insusceptibility to Fertility Levels in Uganda: An Application of the Aggregate Fertility Model, Fertility Research and Practice, 1(1), pp.1-8.

Rutayisire, P.C., Hooimeijer, P., \& Broekhuis, A., 2014. Changes in Fertility Decline in Rwanda: A Decomposition Analysis. International Journal of Population Research, 2014, pp.110.

Rutenberg., Naomi., Mohamed, A., Luis, H.O., \& Marilyn, W., 1991. Knowledge and Use of Contraception. Demographic and
Health Surveys Comparative Studies, 6. Columbia, Maryland: Institute for Resource Development.

Samosir, O, B., McDonald, P., Utomo, A., Hull, T., Herartri, R., Fadila, W., Masdar, S., \& Rachmad, S.H., 2018. Fertility Preferences in Indonesia. in Family Demography in Asia. Edward Elgar, pp.171-184.

Samosir, O.B., 1994. Contraceptive Use in Indonesia. University of Southampton.

Samosir, O. B., 2019. Indonesia’s Fertility Decomposition: Analysis Based on the Results of the IDHS in 2017. Jakarta, Indonesia.

Sipsma, H.L., Bradley, E.H., \& Chen, P.G., 2013. Lactational Amenorrhea Method as a Contraceptive Strategy in Niger. Maternal and Child Health Journal, 17(4), pp.654-660.

Sitorus, M.A., 2020. Evaluation of Total Fertility Rate (TFR) North Sumatera Province, 2017 - 2019. Randwick International of Social Science Journal, 1(2), pp.194-204.

Utomo, A.J., 2012. Women as Secondary Earners: Gendered Preferences on Marriage and Employment of University Students in Modern Indonesia. Asian Population Studies, 8(1), pp.65-85.

Wilonoyudho, S., \& Prajanti, S.D.W., 2018. Anomalies in Family Planning in Central Java, Indonesia. Komunitas: International Journal of Indonesian Society and Culture, 10(1), pp.86-91.

Yeung, W.J.J., Desai, S., \& Jones, G.W., 2018. Families in Southeast and South Asia. Annual Review of Sociology, 44, pp.469-495. 